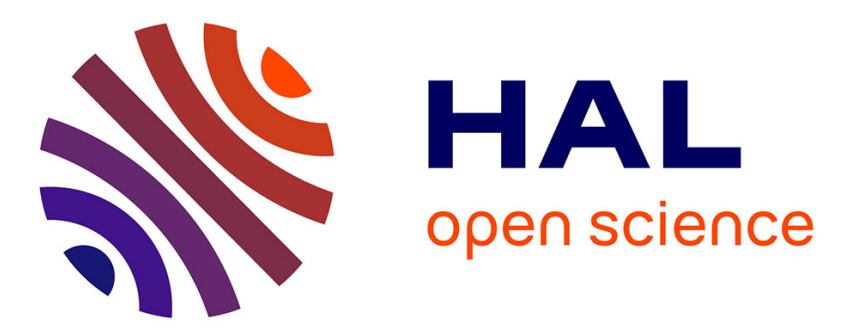

\title{
Evidence of in vitro metabolic interaction effects of a chlorfenvinphos, ethion and linuron mixture on human hepatic detoxification rates
}

\author{
Ali Kadar, Georges de Sousa, Ludovic Peyre, Henri Wortham, Pierre \\ Doumenq, Roger Rahmani
}

\section{To cite this version:}

Ali Kadar, Georges de Sousa, Ludovic Peyre, Henri Wortham, Pierre Doumenq, et al.. Evidence of in vitro metabolic interaction effects of a chlorfenvinphos, ethion and linuron mixture on human hepatic detoxification rates. Chemosphere, 2017, 181, pp.666-674. 10.1016/j.chemosphere.2017.04.116 . hal-01604861

\section{HAL Id: hal-01604861 \\ https://hal.science/hal-01604861}

Submitted on 19 Apr 2018

HAL is a multi-disciplinary open access archive for the deposit and dissemination of scientific research documents, whether they are published or not. The documents may come from teaching and research institutions in France or abroad, or from public or private research centers.
L'archive ouverte pluridisciplinaire HAL, est destinée au dépôt et à la diffusion de documents scientifiques de niveau recherche, publiés ou non, émanant des établissements d'enseignement et de recherche français ou étrangers, des laboratoires publics ou privés. 
1 Evidence of in vitro metabolic interaction effects of a chlorfenvinphos, ethion 2 and linuron mixture on human hepatic detoxification rates

3 Ali Kadar ${ }^{\text {a, b, * }}$, Georges de Sousa ${ }^{\text {b, }}$, Ludovic Peyre ${ }^{\text {b }}$, Henri Wortham ${ }^{\text {a }}$, Pierre Doumenq ${ }^{\text {a }}$, Roger 4 Rahmani ${ }^{\mathrm{b}}$.

5 a Aix Marseille Univ, CNRS, LCE, Marseille, France,

$6 \quad$ *Corresponding author. E-mail address: ali.kadar@etu.univ-amu.fr (A. Kadar)

b INRA, UMR 1331 TOXALIM, Laboratoire de Toxicologie Cellulaire et Moléculaire des Xénobiotiques, BP 167, 400 Route des Chappes, 06903 Sophia Antipolis Cedex, France

\section{ABSTRACT}

General population exposure to pesticides mainly occurs via food and water consumption. However, their risk assessment for regulatory purposes does not currently consider the actual co-exposure to multiple substances. To address this concern, relevant experimental studies are needed to fill the lack of data concerning effects of mixture on human health. For the first time, the present work evaluated on human microsomes and liver cells the combined metabolic effects of, chlorfenvinphos, ethion and linuron, three pesticides usually found in vegetables of the European Union. Concentrations of these substances were measured during combined incubation experiments, thanks to a new analytical methodology previously developed. The collected data allowed for calculation and comparison of the intrinsic hepatic clearance of each pesticide from different combinations. Finally, the results showed clear inhibitory effects, depending on the association of the chemicals at stake. The major metabolic inhibitor observed was chlorfenvinphos. During co-incubation, it was able to decrease the intrinsic clearance of both linuron and ethion. These latter also showed a potential for metabolic inhibition mainly cytochrome P450-mediated in all cases. Here we demonstrated that human detoxification from a pesticide may be severely hampered in case of co-occurrence of other pesticides, as it is the case for drugs interactions, thus increasing the risk of adverse health effects. These results could contribute to 
improve the current challenging risk assessment of human and animal dietary to environmental chemical mixtures.

Keywords:

Health risk assessment, Pesticides mixture, Hepatic clearance, Metabolic interactions, Detoxification.

\section{Introduction}

Synthetic pesticides have helped to increase crop yields of modern agriculture for more than half a century. However, due to their widespread use as insecticides, herbicides, fungicides, fumigants and rodenticides, they are now considered as a major group of contaminants. For the general population, although pesticide use for elimination of pests is a significant route of indoor exposure (Van den Berg et al., 2012), dietary intake including water consumption is considered to be the main source of exposure to most pesticides (Cao et al., 2011; Damalas et al., 2011; Ding, 2014). Thus, food commodities may simultaneously contain different pesticide residues, resulting in an uninterrupted exposure of human populations to complex pesticide mixtures through their diet. Crepet et al. (2013) found that the French population is mainly exposed to 7 different pesticide mixtures composed of two to six compounds (among 79 targeted food pesticides). As the marketing authorization for a chemical substance is delivered at the European Union scale, it could be assumed that the whole European population is likely to be exposed to these same pesticide mixtures. Among these residues, a mixture including two organophosphorus compounds (chlorfenvinphos and ethion) banned since 2007 but not necessarily totally off the agricultural practice (Storck et al., 2017) and a substituted urea (linuron), was found to be frequently present in staple foods such as carrots and potatoes (see Fig. 1).

The organophosphorus insecticide chlorfenvinphos [2-chloro-1-(2,4-dichlorophenyl)vinyl diethyl phosphate] is a neurotoxic molecule which inhibits the acetylcholinesterase. This phosphoorganic pesticide is transformed in mammals by a hepatic oxidative O-deethylation (Hutson and Wright, 1980). Moreover, chlorfenvinphos administration leads to microsomal enzyme induction and alterations of free amino acid concentrations in rat liver (Sedrowicz et al., 1996). In the same way, an 
in vivo study has revealed that chlorvenvinphos decreases the glutathione level and increases the concentrations of hydrogen peroxide and serum total glutathione in liver (Lukaszewicz-Hussain, 2011). Indeed, chlorfenvinphos liver metabolism is associated with cytochrome P450 (CYP) activities resulting in the generation of reactive oxygenated metabolites and oxidative stress (Swiercz et al., 2013).

Ethion $\left(O, O, O^{\prime}, O^{\prime}\right.$-tetraethyl $S, S^{\prime}$-methylene bis(phosphoro-dithioate), is also an organophosphorus insecticide, which presents the same mechanism of action, compared to chlorfenvinphos. Ethion is converted in the liver to its active oxygenated analog, ethion mono-oxon, via desulfuration thanks to cytochrome P-450 enzymes (Desouky et al., 2013).

Linuron, [3-(3,4-dichlorophenyl)-1-methoxy-1-methylurea] is a phenylurea herbicide widely used in agriculture. Human liver is suspected to be a target of linuron, as it induced DNA damages in rat liver (Scassellati-Sforzolini et al., 1997). Another study demonstrated that exposure to linuron leads to hepatocellular adenomas in rat (Santos et al., 2014). Interestingly, this compound was described to be activated in mammalian metabolizing cells leading to an increase of mutagenic properties (Federico et al., 2016). Finally, linuron was shown to be an aryl hydrocarbon receptor (Ahr) ligand and its agonistic activity leads to the induction of CYP1A genes' expression (Takeuchi et al., 2008).

Risk assessment carried out across the world by authorities mainly focus on compounds belonging to the same chemical family, or possessing the same mechanisms of action (Reffstrup et al., 2010; Ragas et al., 2013). In addition, assessment is only based on the evaluation of cumulative effects of these products, supposing the absence of potential effects concerning interactions between pesticides (European Food Safety Agency, 2012). Therefore, a wide thinking process has been started for more than 5 years to address the issue of risk assessment regarding the combined actions of substances on human health (Solecki et al., 2014; European Commission, 2014; Rider et al., 2013). An increasing number of experimental studies have been published in the last few years (Starr et al., 2012; Takakura et al., 2013; Carvalho et al., 2014; Orton et al., 2014; Cedergreen, 2014 Clarke et al., 2015; Spaggiari et al., 2016), helping to fill the gap in knowledge on this topic. More than a decade ago, Tang et al. (2002) already demonstrated a strong inhibition in the metabolism of carbaryl when it was 
simultaneously incubated with chlorpyrifos in human liver sub-cellular preparations. Similarly, Savary et al. (2014) showed that hepatic metabolic interactions occurred during the co-incubation of the pesticides endosulfan and methoxychlor. This phenomenon increases the residence time of the active compounds and thus their latent toxicity. While Savary studied these interactions effects through the activities of the CYP isoforms involved, Tang et al. (2002) used the same experimental strategy. However, they also demonstrated the occurrence of an interaction effect on the basis of calculated intrinsic clearance rates resulting from human liver microsome experiments. An alternative approach to evaluate a metabolic interaction between two compounds consists in comparing the intrinsic clearances of the product when incubated alone, or as a mixture using the substrate depletion approach (Donglu et al., 2007).

Human liver is the most important site of biotransformation in the body, primary culture of hepatocytes and hepatocyte subcellular preparations have proven to be suitable in vitro models for the investigation of the metabolism and metabolic interactions of environmental contaminants (Hodgson et al., 2014). Although liver microsomes support only a part of the whole metabolic process i.e. phase I metabolism, it continues to be the first-line model for metabolism study assays. Indeed, they are more readily available than hepatocytes and specifically adapted to CYP kinetic measurements. In order to highlight the part of phase II metabolism and cellular uptakes, primary culture of hepatocytes can be used as a complement as suggested by Houston and Carlile (1997), who demonstrated that both microsomes and hepatocytes might be suitable for the ranking of specific substrate hepatic intrinsic clearances in rats. Here, we investigated, for the first time, the effect of a co-incubation of multi-class pesticides present as a mixture in the French diet, especially on the human liver metabolism. In order to highlight the possible human metabolic interaction effects of the pesticide mixture, the analytical method previously developed by Kadar et al. (2017) will be applied to this in vitro study.

\section{Materials and methods}

\subsection{Biological samples}

\subsubsection{Human microsomes}


from ten different donors. First, for each individual, microsomes purification was carried out as described by Van der Hoeven and Coon (1974). Then, for sample from each donor, the microsomal protein concentration was quantified according to the method of Bradford (Bio-Rad Protein Assay kit; Ref. 15), using bovine serum albumin as standard. Finally, a pooled microsomal sample was prepared in order to obtain a final concentration of $10 \mathrm{mg} / \mathrm{mL}$ of proteins in $100 \mathrm{mM}$ phosphate potassium buffer (pH 7.4) containing $1.0 \mathrm{mM}$ EDTA and $20 \%$ glycerol $(v / v)$. Aliquots of $1.4 \mathrm{~mL}$ were then stored at $-80{ }^{\circ} \mathrm{C}$.

\subsubsection{Primary culture of human hepatocytes}

All experiments on human tissue were carried out according to the ethical standards of the responsible committee on human experimentation and the Helsinki Declaration. For each of the three livers donated (two females: F31 and F82, one male: M66), hepatocytes were isolated as previously described by Berry and Friend (1969) and submitted to long-term cryopreservation (De sousa et al., 1991). For the present study, they were thawed as established by Rijntjes et al. (1986). Viable cells were suspended in seeding medium I (Williams E Glutamax medium supplemented with penicillin $100 \mathrm{UI} / \mathrm{mL}$, streptomycin $100 \mu \mathrm{g} / \mathrm{mL}$, bovine insulin $0.1 \mathrm{UI} / \mathrm{mL}$ and fetal calf serum $10 \% \mathrm{v} / \mathrm{v}$ ). Cell viability achieved by means of trypan blue exclusion was $80 \%$ or greater, then the number of viable cells was determined using a Malassez cell. The hepatocytes suspended in the seeding medium I were inoculated after appropriate dilution at about $0.7 \times 10^{5}$ cells/well into 48 -wells Corning ${ }^{\circledR}$ Costar ${ }^{\circledR}$ plates (Corning, NY, USA) that had previously been coated with rat tail collagen I (Sigma Aldrich, Saint-Quentin Fallavier, France). All the plates were then placed in an incubator with an atmosphere containing $5 \%$ of $\mathrm{CO}_{2}$ and $95 \%$ of relative humidity for a $24 \mathrm{~h}$ adhesion period. After attachment, the wells were rinsed using medium II (Williams E Glutamax medium supplemented with penicillin $100 \mathrm{UI} / \mathrm{mL}$, streptomycin $100 \mu \mathrm{g} / \mathrm{mL}$, bovine insulin $0.1 \mathrm{UI} / \mathrm{mL}$, hydrocortisone hemisuccinate $1 \mu \mathrm{M}$ and bovine serum albumin $240 \mu \mathrm{g} / \mathrm{mL}$ ) and maintained in contact with the medium until the exposition experiments. 


\subsection{In vitro metabolism experiments}

\subsubsection{Microsomes incubations}

Microsomal samples at a total protein concentration of $0.5 \mathrm{mg} / \mathrm{mL}$ were prepared in $100 \mathrm{mM}$ phosphate buffer ( $\mathrm{pH}$ 7.4) containing a cofactor regenerating system. This latter consisted of $6 \mathrm{mM}$ glucose-6-phosphate, $3 \mathrm{mM}$ nicotinamide adenine dinucleotide phosphate and 0.4 unit of glucose-6phosphate dehydrogenase. Microsomal experiments were carried out in borosilicate glass tubes (volume $6 \mathrm{~mL}$ ) in order to minimize physical adsorption of the pesticides.

A limited volume of $1 \mu \mathrm{L}$ of stock individual solution of chlorfenvinphos, ethion, linuron or their different combination mixtures, prepared in acetonitrile, was deposited in each tube. Then, after a pre-incubation during 5 min at $+37{ }^{\circ} \mathrm{C}$, the microsomal sample was added. Care was taken in order not to exceed a $0.25 \%$ solvent proportion in each tube. The blank sample was prepared using the same volume of pure acetonitrile. The glass tube was incubated for the desired time as described above. At the end of the experiments, the reactions were stopped by transferring tubes in an ice bath and by adding $400 \mu \mathrm{L}$ of ice-cold acetonitrile to each tube before vortex stirring.

Firstly, for Michaelis-Menten experiments, independent compounds were incubated at $+37^{\circ} \mathrm{C}$ with the human microsomal sample in triplicate, at three increasing concentrations for chlorfenvinphos $(0.5,1$ and $2 \mu \mathrm{M})$, ethion $(1,2$ and $4 \mu \mathrm{M})$ and linuron $(3,6$ and $12 \mu \mathrm{M})$. The reactions were stopped after 4, 7, 11 and $21 \mathrm{~min}$.

Secondly, on the base of the initial results, the Michaelis apparent affinity constant $\left(K_{m, a p p}\right)$ was determined for each xenobiotic as described in the data analysis part (see 2.3), and the metabolic influence of co-incubations was studied. To achieve this goal, a single concentration of $0.2 K_{m, a p p}$ of each pesticide was incubated alone as a reference, with concentrations of $0.5 K_{m, a p p}$ and $5 K_{m, a p p}$ of each other compounds and with both of them at the aforementioned levels. The assays carried out in triplicate were quenched as described above at 3.5, 6.5 and 9.5 min. 


\subsubsection{Hepatocytes incubations}

In each seeded well, the seeding medium was removed and substituted by $200 \mu \mathrm{L}$ of the same medium supplemented with the required amount of the pesticides in order not to exceed $0.25 \%$ DMSO solvent proportion, and pre-incubated in the preparation glass tube at $+37^{\circ} \mathrm{C}$ during 5 min. The blank seeded well consisted of the same percentage of pure DMSO solvent. After 5, 9, 15 or $22 \mathrm{~h}$, the hepatocytes were scraped and homogenized by a gentle manual agitation after immediate addition of $200 \mu \mathrm{L}$ ice-cold acetonitrile.

First, to determine the Michaelis-Menten parameters, cells from three donors F31 (31-yearold female), F82 (82-year-old female) and M66 (66-year-old male) were exposed to the pesticides at four increasing concentrations of chlorfenvinphos $(2,4,8,12 \mu \mathrm{M})$, ethion $(4,8,12,20 \mu \mathrm{M})$ and linuron $(6,12,18,24 \mu \mathrm{M})$. All the reactions were stopped after 5, 9, 15 and $22 \mathrm{~h}$ as reported above. Secondly, after determination of the Michaelis apparent affinity constant $\left(K_{m, a p p}\right)$ of each pesticide, the effect of co-incubation on individual metabolism was studied. To realize this aim, a single concentration of $0.1 K_{m, a p p}$ of each pesticide was incubated alone as a reference, with concentrations of $0.1 K_{m, a p p}$ and $0.5 K_{m, a p p}$ of each other compounds and with both of them at the same last two levels. Each experiment was performed in triplicate with pools of hepatocytes from the three individuals mentioned above (i.e. pooled after thawing) in order to represent an average human donor pool. Consequently, the pesticides dependent $K_{m, a p p}$ values were calculated as the average of the specific constants of each individual. The incubations were finalized after 5, 10 and $15 \mathrm{~h}$ as described above.

\subsection{Data analysis}

Michaelis-Menten affinity constants $\left(K_{m, a p p}\right)$ and rates of intrinsic clearance $\left(C L_{i n t}\right)$ were calculated from parent compound depletion data. For $K_{m, a p p}$ determination, concentration of pesticide remaining over the time course was determined thanks to the analytical method presented by Kadar et al. (2017). Moles of pesticide remaining were then converted into moles of product formed and, plotted versus time to allow determination of the kinetic reaction after nonlinear least square regression analysis using GraphPad Prism6 software (Ritme, Paris, France). In order to reduce the 
number of compound concentrations needed to accurately determine Michaelis-Menten kinetic parameters, the alternative direct-linear plot approach (Eisenthal and Cornish-Bowden, 1974) was employed. According to this method, for each pesticide, only two to four pesticide concentrations were needed to calculate $K_{m, a p p}$. Finally, intrinsic clearances were determined directly using the in vitro half-life method (Obach, 1999). A regression analysis was carried out to determine $T_{1 / 2}$ value, before a conversion to $C L_{\text {int }}$ as described by the formulas (1) to (3) presented below.

$$
S=S_{0} \times e^{-k t} \quad \text { (1) }
$$

Where $S(\mu \mathrm{M})$ is the remaining substrate (pesticide) concentration, $S_{0}$ the initial substrate concentration $(\mu \mathrm{M})$ and $k$ the elimination rate constant $\left(\min ^{-1}\right.$ or $\left.\mathrm{h}^{-1}\right)$

$$
T_{1 / 2}=\frac{-0.693}{k} \quad(2)
$$

Where $T_{1 / 2}$ is the half-life value for respectively microsomes (min) and hepatocytes assays (h)

$$
C L_{\text {int }}=\frac{0.693}{T_{1 / 2}} \times \frac{V_{i}}{Q}
$$

Where $V i$ is the incubation volume $(\mathrm{mL})$ and $Q$ the proteins amount $(\mathrm{mg})$

\section{Results and discussion}

\subsection{Microsomes metabolism study}

The in vitro metabolism of each pesticide was first investigated using human liver microsomes. Incubation mixtures of each target analyte displayed no biotransformation when experiments were performed in the absence of a NADPH-generating system, implying a CYP dependent metabolism. As shown in Fig. 2 and summarized in Table 1, the $K_{m, a p p}$ values obtained after data processing for each pesticide were, $4.2 \pm 0.3 \mu \mathrm{M}, 8.0 \pm 0.3 \mu \mathrm{M}$ and $2.0 \pm 0.1 \mu \mathrm{M}$ for chlorfenvinphos, ethion and linuron respectively. 
As decribed by Obach (1999), we assumed that an approximate value of $0.2 K_{m, a p p}$ was well

below the $K_{m, a p p}$. Then, level values of $0.4 \mu \mathrm{M}$ for linuron, $0.8 \mu \mathrm{M}$ for chlorfenvinphos and $1.6 \mu \mathrm{M}$ for ethion should be on the part of the saturation curve where initial rates correlate with $\mathrm{CL}_{\mathrm{int}}$. The in vitro half-life data collected from individual and simultaneously incubated pesticides allowed the final calculation of the hepatic intrinsic clearances displayed in Table 2.

Firstly, the human liver microsomal intrinsic clearance of linuron pesticide $(0.681 \mathrm{~mL} / \mathrm{min} / \mathrm{mg})$ was not clearly impaired when the lowest concentrations of either chlorfenvinphos $(2 \mu \mathrm{M})$ or ethion $(4 \mu \mathrm{M})$ were individually added. Indeed, their respective intrinsic clearances were 0.678 and $0.672 \mathrm{~mL} / \mathrm{min} / \mathrm{mg}$, which was not noticeably different from the linuron's intrinsic clearance. However, their joint-combination at the same low concentrations revealed an important decrease of the linuron intrinsic clearance $(0.499 \mathrm{~mL} / \mathrm{min} / \mathrm{mg})$. In addition, ethion coexposure at $40 \mu \mathrm{M}$ slightly changed the intrinsic clearance, dividing it by a 1.1 fold. On the contrary, the presence of chlorfenvinphos at $20 \mu \mathrm{M}$ decreased by a 2.7 fold linuron's biotransformation. An interesting synergistic effect could be noticed when linuron was co-incubated with a mixture of ethion and chlorfenvinphos at their highest levels, leading to a 3.7 fold drop off of the intrinsic linuron's intrinsic clearance.

Chlorfenvinphos intrinsic clearance was $1.069 \mathrm{~mL} / \mathrm{min} / \mathrm{mg}$ when the pesticide was incubated alone. Low amounts of either linuron or ethion did not clearly influence its intrinsic clearance. However, we observed a remarkable effect on the original intrinsic clearance when chlorfenvinphos was individually co-incubated with the highest amounts of linuron $(10 \mu \mathrm{M})$ or ethion $(40 \mu \mathrm{M})$. Indeed, in each condition, we noticed a decrease of approximately 1.5 and 1.4-fold, respectively. Moreover, the presence of a mixture containing these two inhibitors at their highest levels induced a comparable division (1.5 fold) of chlorfenvinphos' intrinsic clearance, suggesting that a competitive interaction was very likely to occur in this case.

Finally, in the third and last experimental conditions, ethion's intrinsic clearance $(0.802 \mathrm{~mL} / \mathrm{min} / \mathrm{mg})$ was not clearly modulated by the presence of linuron, whatever the concentration level. On the other hand, when co-incubated with chlorfenvinphos at its low level, ethion's intrinsic 
clearance was divided by a 1.3 -fold and, at its highest level by a 2.7 -fold. The decrease reached a 3.5 fold when ethion was incubated with a mixture of the two other pesticides at their highest levels.

As a consequence, these results obtained from the microsomes metabolism study showed that even if each compound of the studied mixture revealed inhibiting actions, chlorfenvinphos was the most potent inhibitor. Added separately to linuron or ethion, it greatly inhibited the metabolization of these two pesticides with intrinsic clearance values close to those observed in the mixture exposition conditions. Moreover, as weaker inhibitors, linuron and ethion failed to exert such inhibitory effect when they were in turn added to chlorfenvinphos. This suggested once again the predominant role of chlorfenvinphos in the inhibition of the hepatic intrinsic clearance.

\subsection{Hepatocytes metabolism study}

The second part of the study enabled to examine the in vitro metabolism of each phytosanitary product, using primary cultures of human hepatocytes. This step allowed evaluating whether the mixture interactions revealed above could be confirmed with the use of the considered "gold model", knowing that freshly isolated hepatocytes, express all the hepatic enzymes and transporters required for complete metabolism studies (Fasinu et al., 2012).

Firstly, as depicted in Fig. 3 and summarized in Table 1, the $K_{m, a p p}$ values of each pesticide were estimated for the different liver cells. We found that the three donors presented a 2 to 3 -fold inter-individual variability, while F82 exhibited the highest affinity values (i.e. lowest values for Km), followed by M66 and F31. The average $K_{m, a p p}$ values were, $42.2 \pm 24.8 \mu \mathrm{M}, 43.0 \pm 14.1 \mu \mathrm{M}$ and $20.0 \pm 13.2 \mu \mathrm{M}$ for chlorfenvinphos, ethion and linuron, respectively. Concentrations of $2.0 \mu \mathrm{M}$ for linuron, $4.0 \mu \mathrm{M}$ for chlorfenvinphos and also $4.0 \mu \mathrm{M}$ for ethion were chosen greatly below the $K_{m, a p p}$. so as to be located in the range where each individual intrinsic clearance is constant, as presented above in the microsomes model. The data obtained from individually and simultaneously exposed pesticides are summarized in Table 3 .

The human hepatocyte intrinsic clearance of chlorfenvinphos was $5.25 \mathrm{~mL} / \mathrm{h} / \mathrm{mg}$. When coexposed with the highest dose of either linuron or ethion, the intrinsic clearance was reduced until 3.69 and $4.18 \mathrm{~mL} / \mathrm{h} / \mathrm{mg}$ respectively. The presence of ethion and linuron at low concentrations produced a 
noticeable but limited effect, whereas a strong inhibition was observed at high concentrations resulting in a 1.7-fold decrease of the chlorfenvinphos intrinsic clearance.

When incubated alone, ethion's intrinsic clearance was $5.07 \mathrm{~mL} / \mathrm{h} / \mathrm{mg}$. Even if a slight inhibitory effect appeared with a decrease of this intrinsic clearance until approximately $4.70 \mathrm{~mL} / \mathrm{h} / \mathrm{mg}$ when chlorfenvinphos and linuron were individually co-incubated at $10 \mu \mathrm{M}$ or $4 \mu \mathrm{M}$ respectively, a more pronounced decrease of about a 1.1-fold, was observed when these two pesticides were present as a mixture at their lowest concentrations. Moreover, chlorfenvinphos had a more important influence when it was co-incubated at its highest concentration $(20 \mu \mathrm{M})$ with ethion, decreasing the ethion's intrinsic clearance by a 1.3 -fold. The concomitance of ethion with the highest levels of a mixture of chlorfenvinphos and linuron lead to reach a 1.7-fold reduction in its hepatic detoxification.

Linuron intrinsic clearance was $2.95 \mathrm{~mL} / \mathrm{h} / \mathrm{mg}$ when exposed alone at $2.0 \mu \mathrm{M}$ to hepatocytes cells. This value remained unchanged when the lowest amounts of ethion or chlorfenvinphos were also present. However, as for the precedent pesticide, a slight decrease of about 1.1-fold was calculated when these substances were both added to the cellular medium at their lowest concentrations. This decrease of the clearance also reached an approximate 1.3-fold at the highest chlorfenvinphos concentration $(20 \mu \mathrm{M})$. Lastly, linuron's intrinsic clearance was divided by about a 1.8 -fold when this pesticide was incubated in the presence of a mixture of the two other compounds at their highest concentrations $(20 \mu \mathrm{M})$.

Thus, the observations made during the hepatocytes metabolism study showed numerous similarities with the microsomal experiments presented above. Indeed, even if each compound of the studied mixture showed a capacity to hamper the degradation of the other pesticides, chlorfenvinphos was the strongest inhibitor among the three pesticides under study. Overall, the co-incubations of the studied compounds on both microsomes and hepatocytes depicted similar metabolic effects. We thus suggest that the intrinsic clearance inhibitions could be mainly due to the inhibition of phase I metabolic enzymes, with minor involvement of other cellular enzymes and membrane transporters. Indeed, herbicides from phenylurea family are known to be mainly metabolized by human CYP1A2, CYP2C19 and CYP3A4 enzyme isoforms and also, but less importantly, by CYP2B6 (Abass et al., 
2007). On the other hand, human organophosphorus metabolism is mainly CYP1A2, CYP2B6, CYP2C9, CYP2C19 and CYP3A4 mediated (Hodgson et al., 2007). As a consequence, this confirms that chlorfenvinphos, ethion and linuron share a common support by CYP for their detoxification and, are likely to compete for the same active sites, resulting in the decrease of their respective intrinsic clearance as experimentally observed above. Moreover, among these phase I enzymes, CYP1A2, CYP2B6 and CYP3A4 are known to be most active in the formation of active oxon phosphate metabolites (Buratti et al., 2004). During this activation by oxidative desulfuration reaction, the release of highly reactive sulfur results in irreversible CYP inhibitions (Hodgson et al., 2007). This is precisely what could happen with ethion but not with chlorfenvinphos which, in contrast to most organophosphorus pesticides, presents an already desulfurated active parent form (Carter et al., 2010) as shown by its typical oxon chemical structure (Fig. 1). Therefore, the potent inhibitory characteristic shown by this compound may be explained through the action of other enzymes.Furthermore, the noticeable difference in intrinsic clearances between human liver models mentioned above might be due to the faster metabolization of chlorfenvinphos in cells. Indeed, as an oxon, the most potent inhibitor of the pesticide mixture should be more easily metabolized through the hydrolytic action of hepatic paraoxonase, which is far less present in microsomes than in hepatocytes (Gonzalvo et al., 1997).

\section{Conclusions}

In this work, a metabolism study on chlorfenvinphos, ethion and linuron mixture was conducted. It aimed at exploring the possible pesticide-pesticide(s) human liver metabolic interactions through the monitoring of the in vitro loss of the parent compound. A minimized number of assays provided the Michaelis-Menten $K_{m, a p p}$ parameter for each compound after Eisenthal and CornishBowden velocities plotting. Based on combined incubations of the active substances, interaction experiments showed clear inhibition effects in both human liver microsomes and hepatocytes. Even if all the compounds showed an action, the rank order of the individual inhibitory potency was chlorfenvinphos >> linuron > ethion. In liver microsomes, the major metabolic inhibitions were 
observed after ethion and linuron concomitant treatments, with a high level of the two other products displaying respectively a 3.5 and 3.7 fold reduction of their intrinsic clearance. These inhibitions were also observed in primary cultures of hepatocytes but were reduced by approximately a half. We hypothesized that it might be linked to a decrease in chlorfenvinphos'inhibitory strength, due to the presence in the liver cells of much greater paraoxonase amounts.

Moreover, the similar trends revealed by the two human liver models demonstrated that the metabolic interactions were mainly mediated by phase I enzymes, probably CYP1A2, CYP2C19, CYP3A4 and CYP2B6.

To conclude, we found evidence of in vitro metabolic interaction effects of a chlorfenvinphos, ethion and linuron mixture on human hepatic detoxification rates. As the consumption of vegetables such as potatoes or carrots proved to have an impact on hepatic intrinsic clearances of these pesticides, we can hypothesize that in France, at the European scale and very probably also abroad, due to a delay in the detoxification of the body, people may be exposed to an increased toxicity of these pesticides. Both experiments using CYP isoforms and paraoxonase, and a comprehensive study focusing on additivity, synergism, and antagonism interactions of the studied mixture should be useful. The results of this work may already encourage safety agencies to include the issue of pesticide mixtures in dietary and environmental risk assessment processes. The methodology described in this work could be applied for future studies on harmful chemical mixtures present in humans and animals' diets, as well as in their environment.

\section{Acknowledgements}

This work was funded by the Agence Nationale de la Recherche (under reference ANR-2008CESA-016-01), by the Office National de l'Eau et des Milieux Aquatiques (ONEMA) and by the Agence Nationale de SÉcurité Sanitaire de l'alimentation, de l'environnement et du travail (ANSES) in the frame of the MEPIMEX Project. The authors also gratefully acknowledge the supply of the LCMS/MS system at Laboratoire de l'environnement de Nice as a collaboration agreement with Patricia Pacini. 


\section{References}

Berry, M.N., Friend, D.S, 1969. High-yield preparation of isolated rat liver parenchymal cells: a biochemical and fine structural study. J. Cell Biol. 43, 506-20.

Cao, L.L., Yan, C.H., Yu, X.D., Tian, Y., Zhao, L., Liu, J.X., Shen, X.M., 2011. Relationship between serum concentrations of polychlorinated biphenyls and organochlorine pesticides and dietary habits of pregnant women in Shanghai. Sci. Total Environ. 409, 2997-3002.

Carlile, D.J., Hakooz, N., Bayliss, M.K., Houston, J.B., 1999. Microsomal prediction of in vivo clearance of CYP2C9 substrates in humans. Br. J. Clin. Pharmacol. 47, 625-635.

Carter W.G., Tarhoni M.H., Ray D.E., 2010. Analytical approaches to investigate protein-pesticide adduct. J Chromatogr B Analyt Technol Biomed Life Sci. 878:1312-1319.

Carvalho, R.N., Arukwe, A., Ait-Aissa, S., Bado-Nilles, A., Balzamo, S., Baun, A., Belkin, S. et al., 2014. Mixtures of chemical pollutants at European legislation safety concentrations: how safe are they? Toxicol. Sci. 141, 218-233.

Cedergreen, N., 2014. Quantifying synergy: a systematic review of mixture toxicity studies within environmental toxicology. PLoS One. 9, 1-12.

Clarke, R., Connolly, L., Frizzell, C., Elliott, C.T., 2015. Challenging conventional risk assessment with respect to human exposure to multiple food contaminants in food: A case study using maize. Toxicol. Lett. 238, 54-64.

Damalas, C.A., Eleftherohorinos, I.G., 2011. Pesticide Exposure, Safety Issues, and Risk Assessment Indicators. Int. J. Environ. Res. Public Health. 8, 1402-1419.

Desouky M.M., Abdel-Gawad H., Hegazi B., 2013. Distribution, fate and histopathological effects of ethion insecticide on selected organs of the crayfish, Procambarus clarkii. Food Chem. Toxicol. 52, 42-52. 
De Sousa, G., Dou, M., Barbe, D., Lacarelle, B., Placidi, M., Rahmani, R., 1991. Freshly isolated or cryopreserved human hepatocytes in primary culture: Influence of drug metabolism on hepatotoxicity. Toxicol. In Vitro 5, 483-486.

Ding, G., 2014. Revisiting pesticide exposure and children's health: focus on China. Sci. Total Environ. 472, 289-295.

Donglu, Z, Mingshe, Z., Griffith Humphreys, W., 2007. Drug Metabolism in Drug Design and Development: Basic Concepts and Practice http://onlinelibrary.wiley.com/doi/10.1002/9780470191699.fmatter/pdf.

Eisenthal, R., Cornish-Bowden, A., 1974. The direct linear plot. A new graphical procedure for estimating enzyme kinetic parameters. Biochem. J. 139, 715-20.

European Commission (2014) Assessment of Mixtures-Review of Regulatory Requirements and Guidance. <https://ec.europa.eu> (Accessed 5 June 2015).

European Food Safety Agency (2012). Scientific Report on Investigation of the state of the science on combined actions of chemicals in food through dissimilar modes of action and proposal for sciencebased approach for performing related cumulative risk assessment. Available from <www.efsa.europa.eu> (Accessed 5 June 2015).

Federico, C., Palmieri,C., Pappalardo, A.M., Ferrito, V., Pappalardo, M., Librando V., Saccone, S., 2016. Mutagenic properties of linuron and chlorbromuron evaluated by means of cytogenetic biomarkers in mammalian cell lines. Environ Sci Pollut Res Int. 23, 17018-25.

Hodgson, E., Wallace, A.D., Shah, R.R., Choi, K., Joo, H., 2014. Human Variation and Risk Assessment: Microarray and Other Studies Utilizing Human Hepatocytes and Human Liver Subcellular Preparations. J. Biochem. Mol. Toxicol. 1, 1-10.

Hodgson, E. and Rose R.L., 2007. Human metabolic interactions of environmental chemicals.

J. Biochem. Mol. Toxicol. 21: 182-6. 
Houston, J.B., Carlile, D.J., 1997. Prediction of hepatic clearance from microsomes, hepatocytes and liver slices. Drug Metab. Rev. 29, 891-922.

Lukaszewicz-Hussain, A., 2011. Liver and serum glutathione concentration and liver hydrogen peroxide in rats subchronically intoxicated with chlorfenvinphos--organophosphate insecticide. Med Pr. 62, 23-9.

Obach, R.S., 1999. Prediction of human clearance of twenty-nine drugs from hepatic microsomal intrinsic clearance data: An examination of in vitro half-life approach and nonspecific binding to microsomes. Drug Metab. Dispos. 27, 1350-9.

Orton, F., Ermler, S., Kugathas, S., Rosivatz, E., Scholze, M., Kortenkamp, A., 2014. Mixture effects at very low doses with combinations of anti-androgenic pesticides, antioxidants, industrial pollutant and chemicals used in personal care products. Toxicol. Appl. Pharmacol. 278, 201-8.

Ragas, A.M., Holmstrup, M., 2013. Tools and perspectives for assessing chemical mixtures and multiple stressors. Toxicology. 313, 73-82.

Reffstrup, T.K., Larsen, J.C., Meyer, O., 2010. Risk assessment of mixtures of pesticides. Current approaches and future strategies. Regul. Toxicol. Pharmaco. 56, 174-192.

Rider, C.V., Carlin, D.J., De Vitoa, M.J., Thompson, C.L., Walkera, N.J., 2013. Mixtures research at NIEHS: An evolving program. Toxicology. 313, 94-102.

Santos, S.M., Videira, R.A., Fernandes, M.A., Santos, M.S., Moreno, A.J., Vicente, J.A., Jurado, A.S., 2014. Toxicity of the herbicide linuron as assessed by bacterial and mitochondrial model systems. Toxicol In Vitro. 28, 932-9.

Savary, C.C, Jossé, R., Bruyère, A., Guillet, F., Robin, M.A., Guillouzo, A., 2014. Interactions of endosulfan and methoxychlor involving CYP3A4 and CYP2B6 in human HepaRG cells. Drug Metab. Dispos. 42, 1235-1240. 

genotoxicity of pure and commercial linuron. Mutat Res. 390, 207-21.

Sedrowicz, L., Witkowska, D., Oledzka, R., 1996. Effect of chlorfenvinphos, cypermethrin and their mixture on the intestinal transport of leucine and methionine. J. Appl. Toxicol. 16, 483-9.

Solecki, R., Stein, B., Frische, T., Matezki S, Wogram J, Streloke M., 2014. Paradigm shift in the risk assessment of cumulative effects of pesticide mixtures and multiple residues to humans and wildlife: German proposal for a new approach. J. Verbr. Lebensm. 9, 329-31.

Spaggiari D., Daali Y., Rudaz S., 2016. An extensive cocktail approach for rapid risk assessment of in vitro CYP450 direct reversible inhibition by xenobiotic exposure. Toxicol Appl Pharmacol. Environmentally relevant mixtures in cumulative assessments: an acute study of toxicokinetics and effects on motor activity in rats exposed to a mixture of pyrethroids. Toxicol. Sci. 130, 309-18. European Union. Sci. Total Environ. 575, 1027-1033.

Swiercz, R., Lutz P., Gralewicz, S., Grzelińska, Z., Piasecka-Zelga, J., Wąsowicz, W., 2013. Partial protection from organophosphate-induced cholinesterase inhibition by metyrapone treatment. Int $\mathbf{J}$ Occup Med Environ Health. 26, 636-46.

Takakura, N., Sanders, P., Fessard, V., Le Hégarat, L., 2013. In vitro combined cytotoxic effects of pesticide cocktails simultaneously found in the French diet. Food Chem. Toxicol. 52, 153-62. hydrocarbon receptor agonistic activity in 200 pesticides using a highly sensitive reporter cell line, DR-EcoScreen cells, and in vivo mouse liver cytochrome P450-1A induction by propanil, diuron and linuron. Chemosphere. 74, 155-65. 
437 Tang, J., Cao, Y., Rose, R.L., Hodgson, E., 2002. In vitro metabolism of carbaryl by human 438 cytochrome P450 and its inhibition by chlorpyrifos. Chem-Biol. Interact. 141, 229-241.

439 Van den Berg, H., Zaim, M., Mnzava, A., Hii, J., Dash, A.P., Ejov, M., 2012. Global trends in the use 440 of insecticides to control vector-borne diseases. Environ. Health Perspect. 120, 577-82.

441 Van der Hoeven, T.A., Coon, M.J., 1974. Preparation and properties of partially purified cytochrome 442 P-450 and reduced nicotinamide adenine dinucleotide phosphate-cytochrome P-450 reductase from 443 rabbit liver microsomes. J. Biol. Chem. 249, 6302-10. 
Table 1

Michaelis apparent affinity constant values from human microsomes and hepatocytes for chlorfenvinphos, ethion and linuron

\begin{tabular}{|c|c|c|c|c|c|}
\hline \multirow[t]{3}{*}{ Pesticide } & \multicolumn{5}{|c|}{$K_{m, a p p}(\mu \mathrm{M})$} \\
\hline & \multirow{2}{*}{$\begin{array}{c}\text { Microsomes } \\
\text { *Pool (10 donors, } n=3)\end{array}$} & \multicolumn{4}{|c|}{ Hepatocytes } \\
\hline & & M66 & F31 & F82 & *Average (3 donors) \\
\hline Chlorfenvinphos & $4.2 \pm 0.3$ & 44.9 & 65.5 & 16.2 & $42.2 \pm 25.8$ \\
\hline Ethion & $8.0 \pm 0.6$ & 42.4 & 57.3 & 29.2 & $43.0 \pm 14.1$ \\
\hline Linuron & $2.0 \pm 0.1$ & 14.1 & 35.2 & 10.8 & $20.0 \pm 13.2$ \\
\hline
\end{tabular}

$* \pm$ S.D.

Table 2

Effects of co-incubations on individual human liver microsomes intrinsic clearance

\begin{tabular}{|c|c|c|c|c|c|c|c|}
\hline Target clearance & & & & ubated & $\operatorname{de}(s)$ & & \\
\hline & - & ethi & & chlorfe & hos & & ure \\
\hline $\begin{array}{l}\text { Pesticide } \\
\text { concentrations }(\mu \mathrm{M})\end{array}$ & - & 4 & 40 & 2 & 20 & $4+2$ & $40+20$ \\
\hline$* \mathrm{Cl}_{\text {int }}$ linuron & 0.681 & 0.678 & 0.620 & 0.672 & 0.248 & 0.499 & 0.186 \\
\hline & - & linu & & eth & & & ure \\
\hline $\begin{array}{l}\text { Pesticide } \\
\text { concentrations }(\mu \mathrm{M})\end{array}$ & - & 1 & 10 & 4 & 40 & $1+4$ & $10+40$ \\
\hline${ }^{*} \mathrm{Cl}_{\text {int }}$ chlorfenvinphos & 1.069 & 1.020 & 0.714 & 1.067 & 0.764 & 0.984 & 0.702 \\
\hline & - & linu & & chlorfe & hos & & ure \\
\hline $\begin{array}{l}\text { Pesticide } \\
\text { concentrations }(\mu \mathrm{M})\end{array}$ & - & 1 & 10 & 2 & 20 & $1+2$ & $10+20$ \\
\hline$* \mathrm{Cl}_{\mathrm{int}}$ ethion & 0.802 & 0.767 & 0.748 & 0.623 & 0.292 & 0.593 & 0.227 \\
\hline
\end{tabular}

* expressed in $\mathrm{mL} / \mathrm{min} / \mathrm{mg}$ of human hepatic microsomes

Table 3

Effects of co-incubations on intrinsic clearance of individual human liver hepatocytes.

\begin{tabular}{|c|c|c|c|c|c|c|c|}
\hline Target clearance & & & & cubated & de(s) & & \\
\hline & - & ethi & & chlorf & cos & $\operatorname{mix}$ & \\
\hline $\begin{array}{l}\text { Pesticide } \\
\text { concentrations }(\mu \mathrm{M})\end{array}$ & - & 4 & 20 & 4 & 20 & $4+4$ & $20+20$ \\
\hline$* \mathrm{Cl}_{\text {int }}$ linuron & 2.951 & 2.942 & 2.799 & 2.825 & 2.362 & 2.666 & 1.629 \\
\hline & - & linur & & ethi & & $\operatorname{mix}$ & \\
\hline $\begin{array}{l}\text { Pesticide } \\
\text { concentrations }(\mu \mathrm{M})\end{array}$ & - & 2 & 10 & 4 & 20 & $2+4$ & $10+20$ \\
\hline${ }^{*} \mathrm{Cl}_{\text {int }}$ chlorfenvinphos & 5.250 & 5.084 & 3.688 & 5.215 & 4.174 & 4.9940 & 2.834 \\
\hline & - & linur & & chlorf & 1os & $\operatorname{mix}$ & \\
\hline $\begin{array}{l}\text { Pesticide } \\
\text { concentrations }(\mu \mathrm{M})\end{array}$ & - & 2 & 10 & 4 & 20 & $2+4$ & $10+20$ \\
\hline${ }^{*} \mathrm{Cl}_{\text {int }}$ ethion & 5.067 & 4.827 & 4.707 & 4.725 & 3.890 & 4.576 & 2.965 \\
\hline
\end{tabular}

* expressed in $\mathrm{mL} / \mathrm{h} / \mathrm{mg}$ of human hepatic proteins, $50 \mathrm{mg}$ proteins per gm of liver (Carlile et al., 1999). 


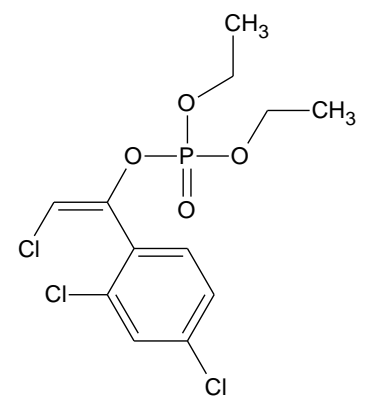

chlorfenvinphos<smiles>CCOP(=S)(OCC)SCSP(=S)(OCC)OCC</smiles>

ethion<smiles>CON(C)C(=O)Nc1ccc(Cl)c(Cl)c1</smiles>

linuron

Fig. 1. Molecular structures of chlorfenvinphos, ethion and linuron 


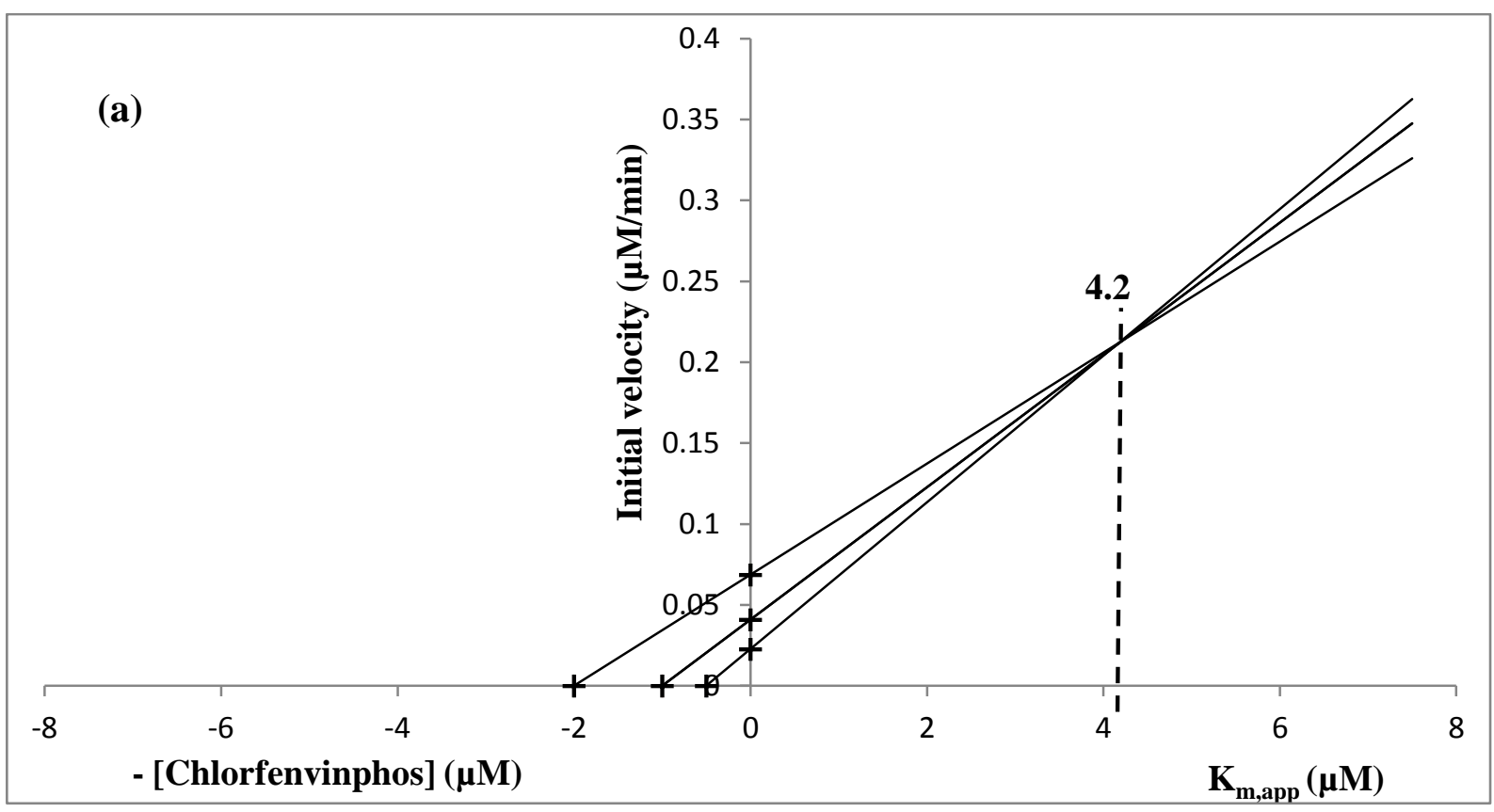

(b)

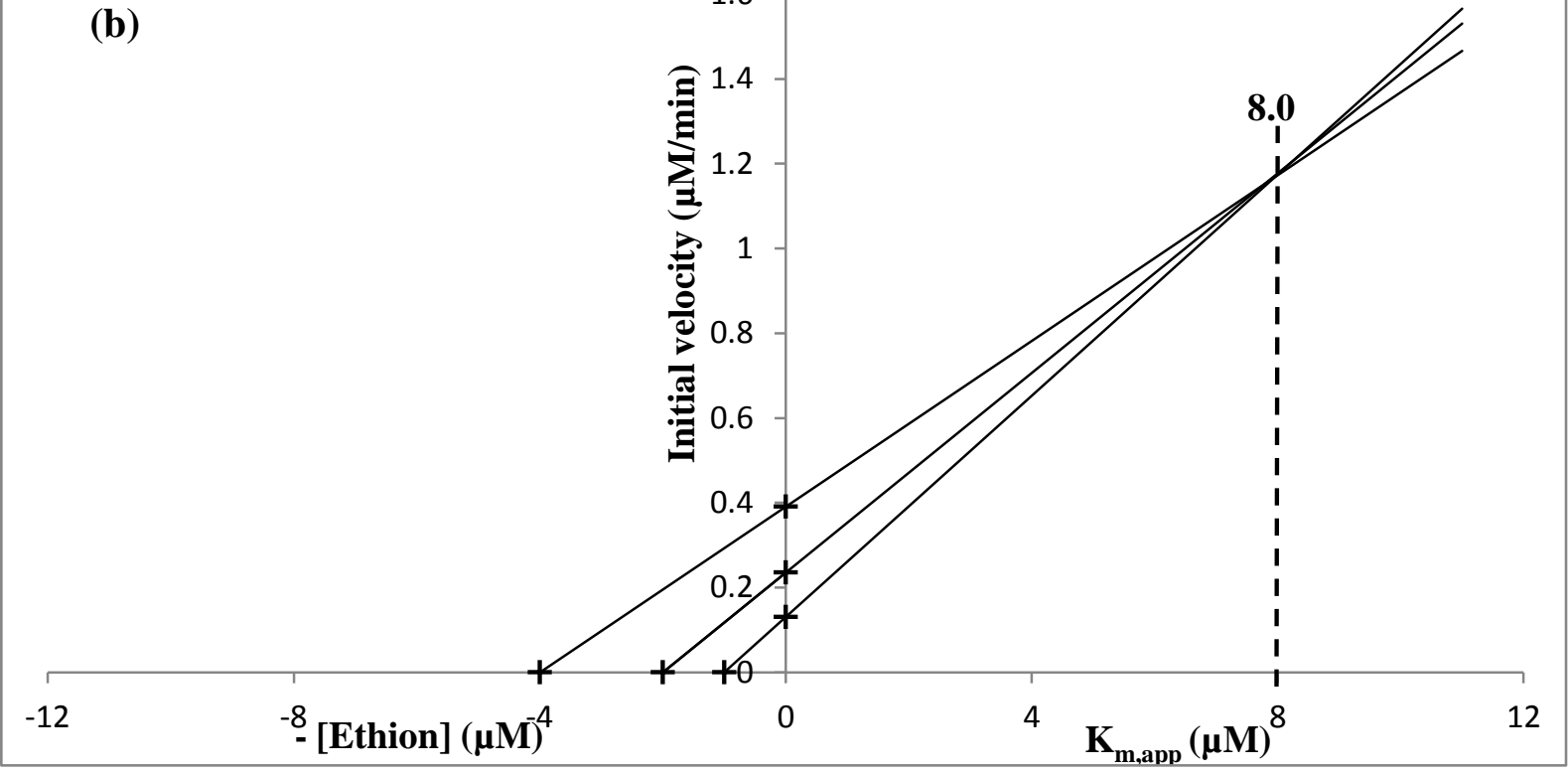




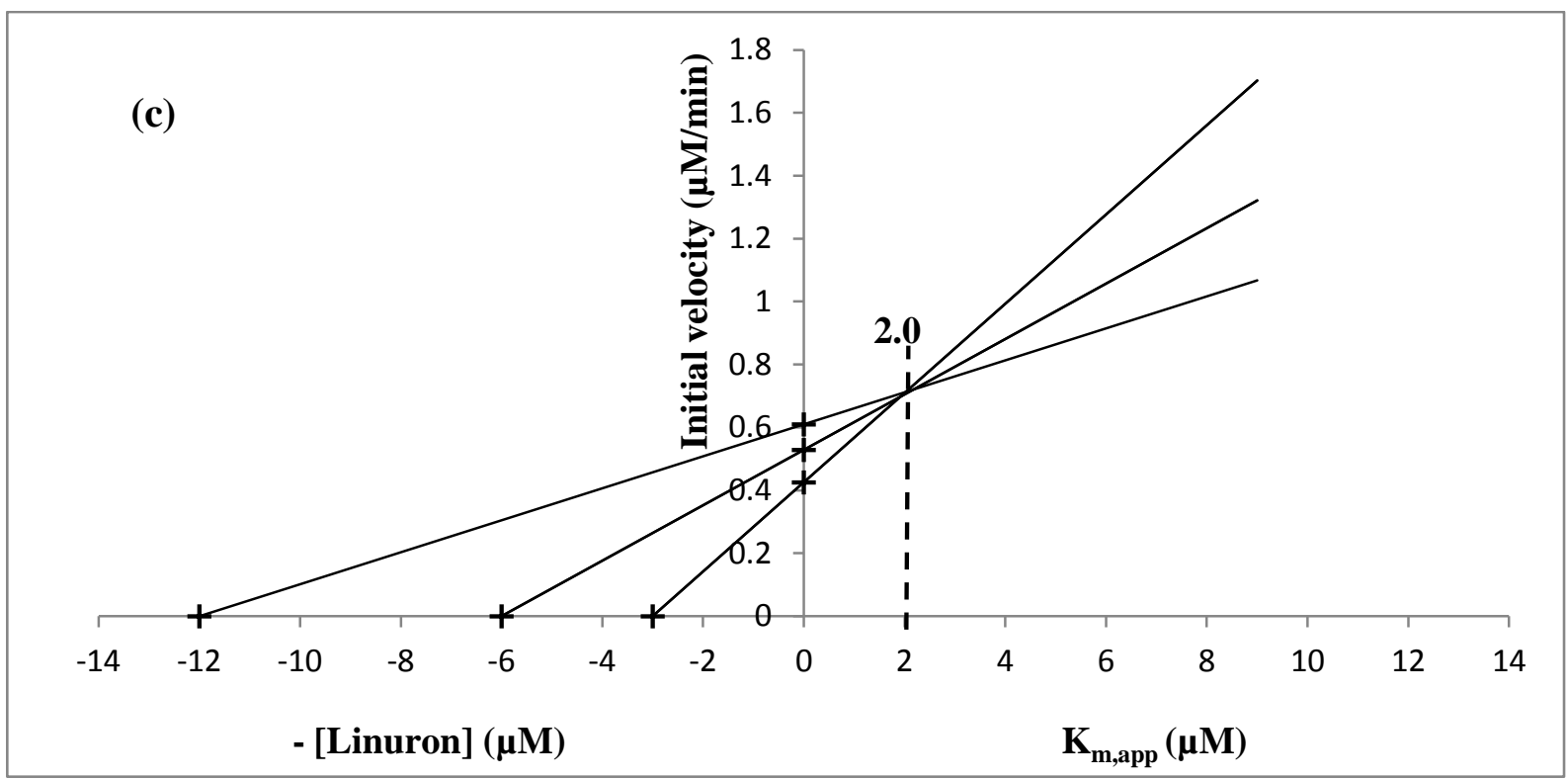

Fig. 2. Estimation of $\mathrm{K}_{\mathrm{m} \text {,app }}$ by the direct linear plot for: (a) chlorfenvinphos, (b) ethion and (c) linuron exposed to microsomes

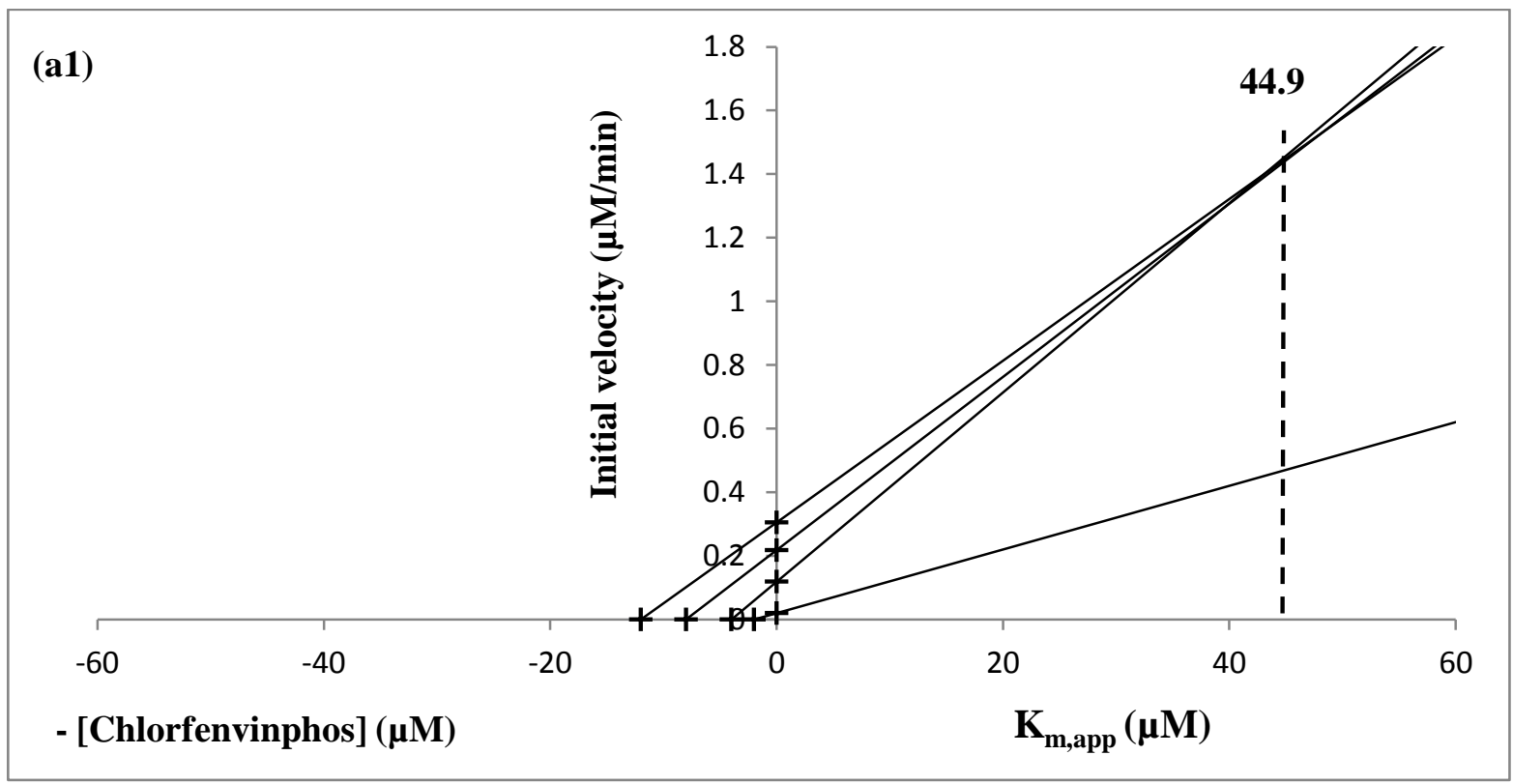



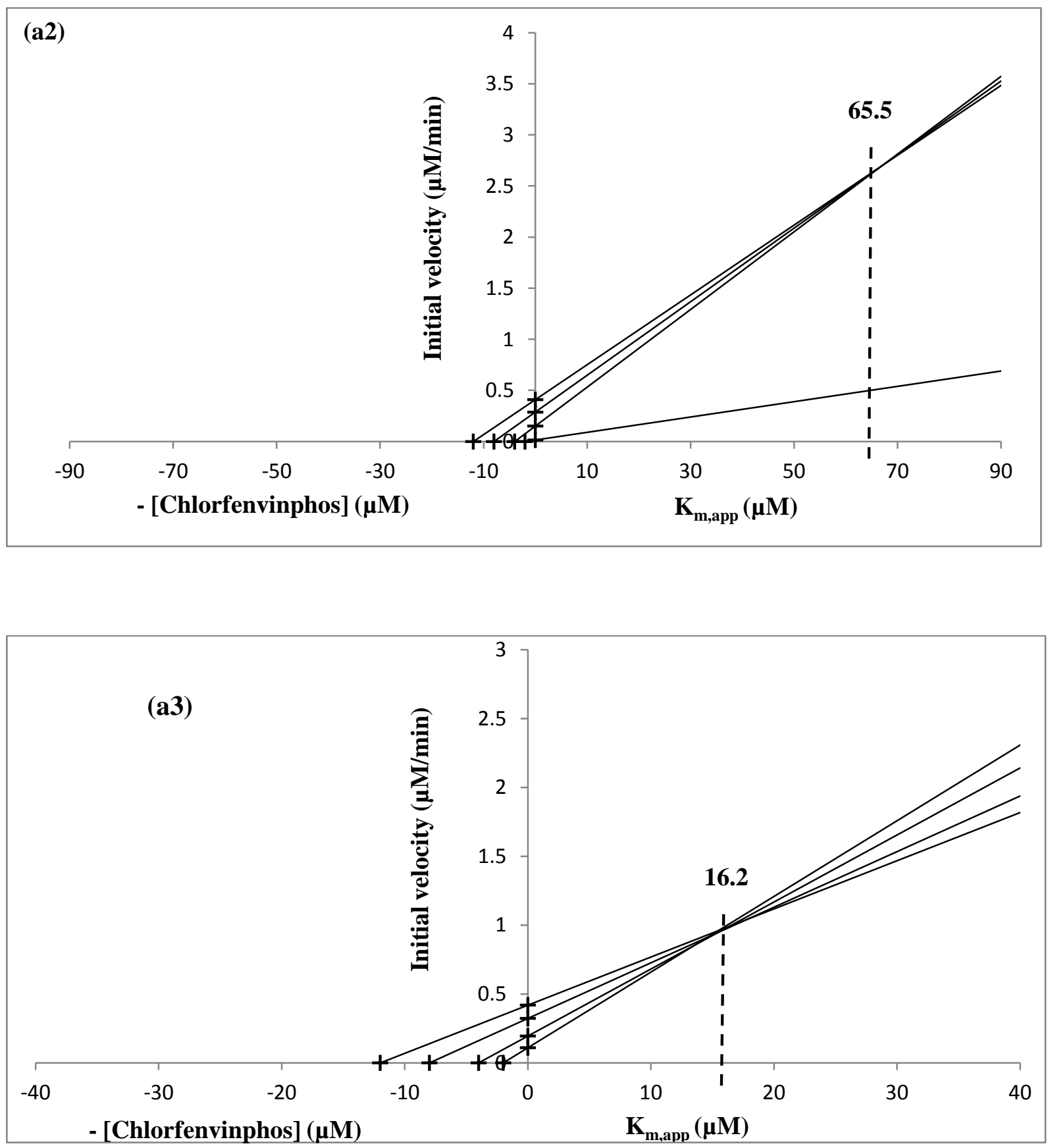

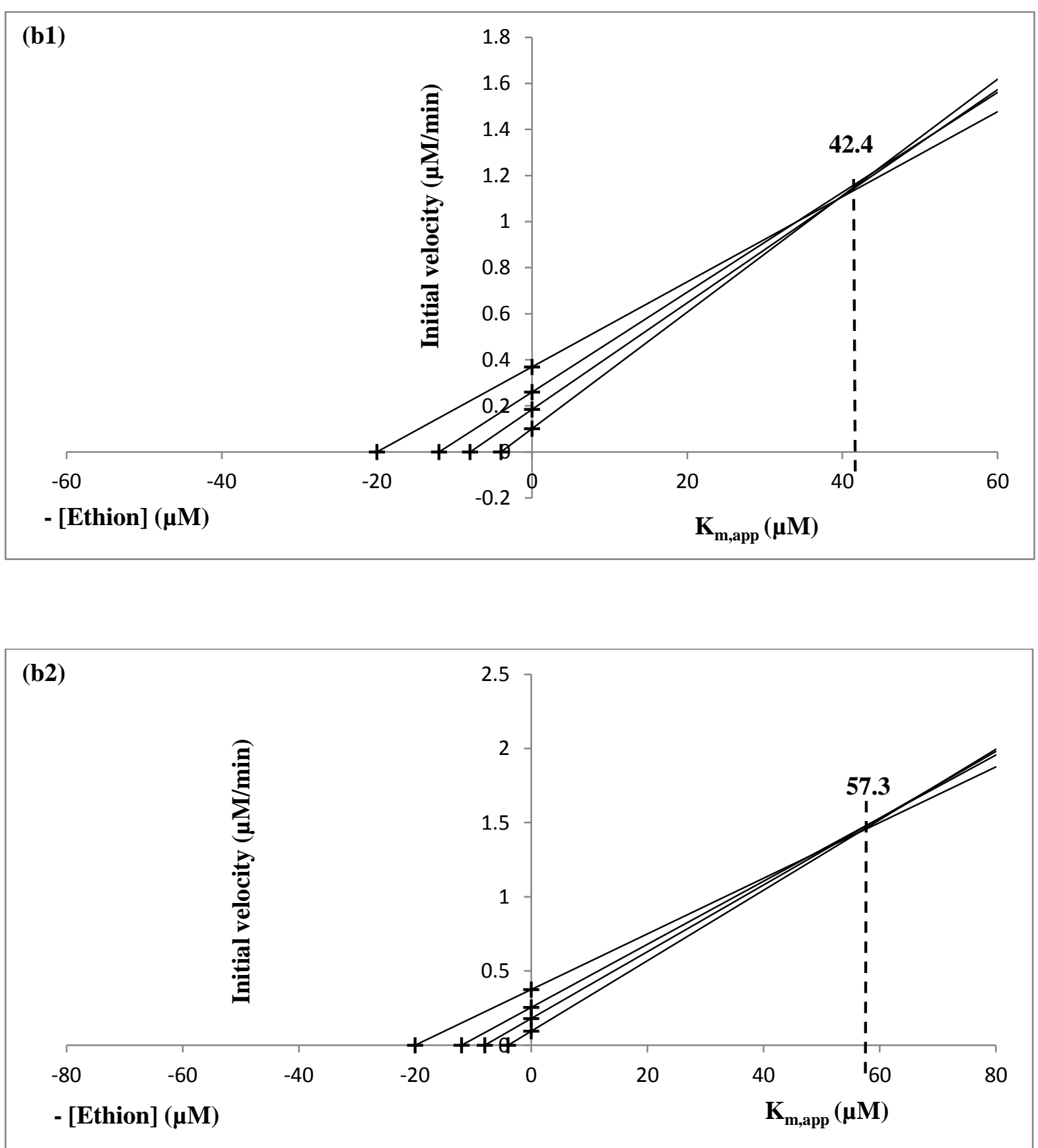

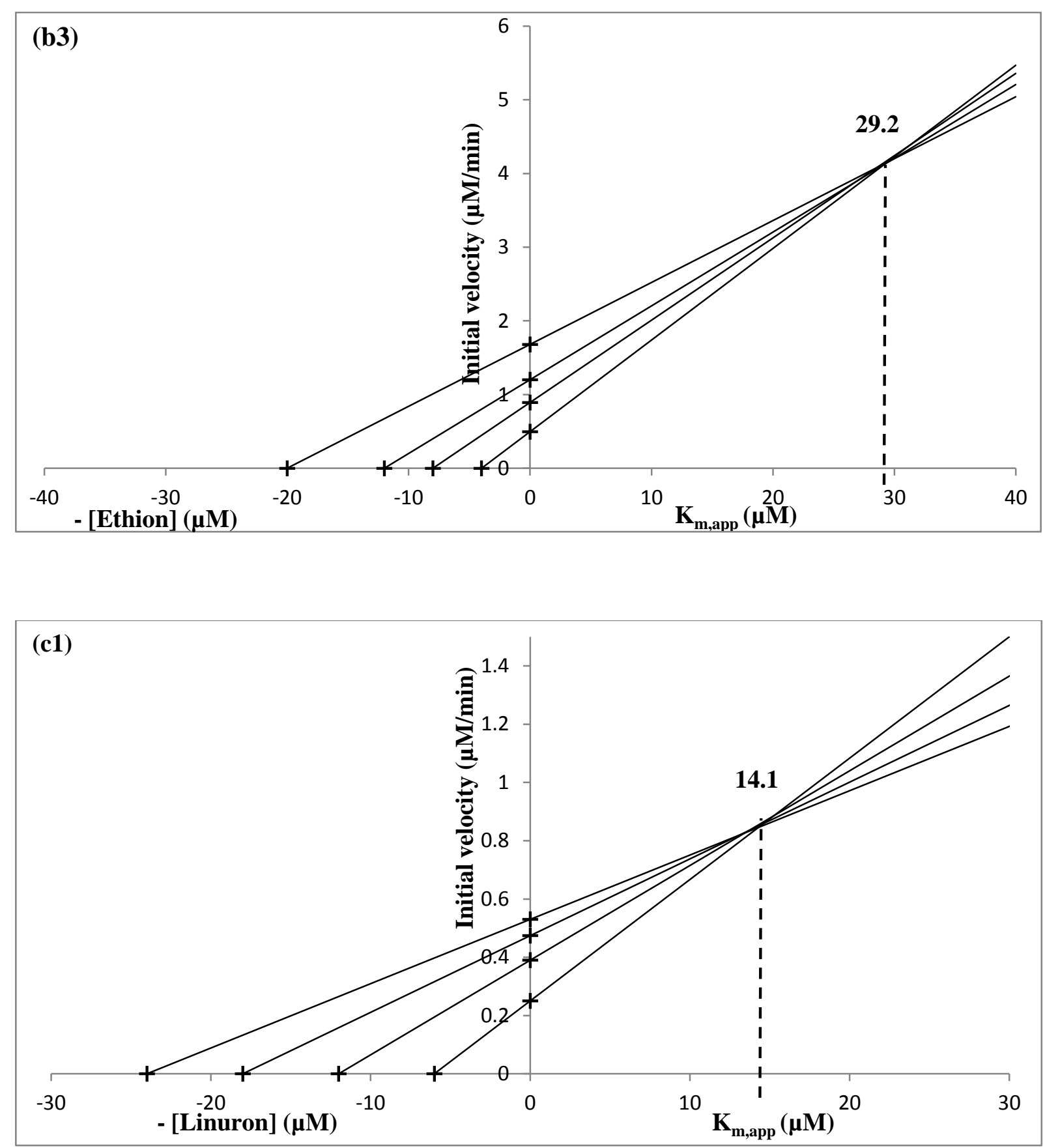

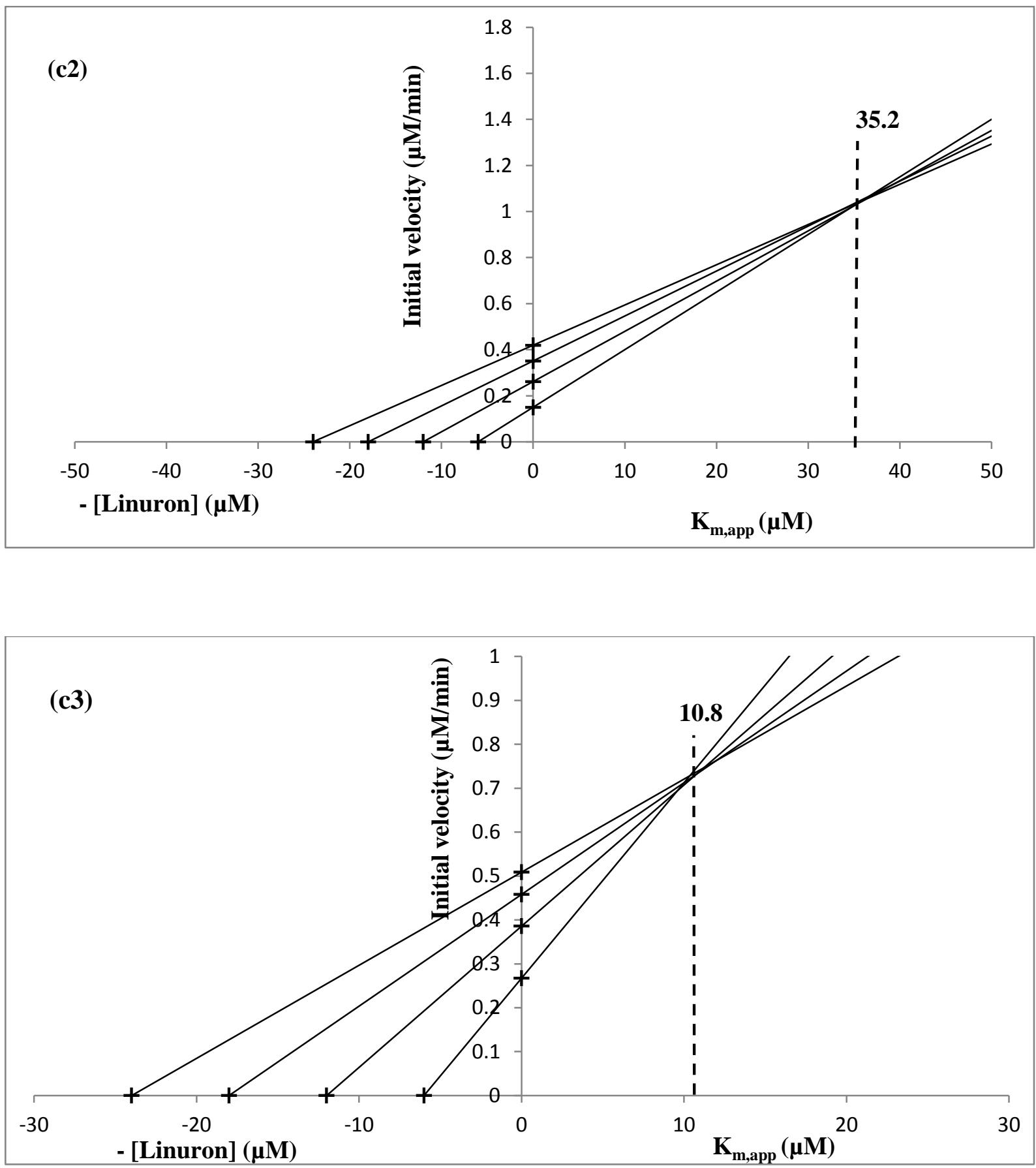

Fig. 3. Estimation of $\mathrm{K}_{\mathrm{m} \text {,app }}$ by the direct linear plot for human hepatocytes: (a1) chlorfenvinphos-M66, (a2) chlorfenvinphos-F31, (a3) chlorfenvinphos-F82, (b1) ethion-M66, (b2) ethion-F31, (b3) ethionF82, (c1) linuron-M66, (c2) linuron-F31, (c3) linuron-F82. 


\begin{abstract}
General population exposure to pesticides mainly occurs via food and water consumption. However, their risk assessment for regulatory purposes does not currently consider the actual co-exposure to multiple substances. To address this concern, relevant experimental studies are needed to fill the lack of data concerning effects of mixture on human health. For the first time, the present work evaluated on human microsomes and liver cells the combined metabolic effects of chlorfenvinphos, ethion and linuron, three pesticides usually found in vegetables of the European Union. Concentrations of these substances were measured during combined incubation experiments, thanks to a new analytical methodology previously developed. The collected data allowed for calculation and comparison of the intrinsic hepatic clearance of each pesticide from different combinations. Finally, the results showed clear inhibitory effects, depending on the association of the chemicals at stake. The major metabolic inhibitor observed was chlorfenvinphos. During co-incubation, it was able to decrease the intrinsic clearance of both linuron and ethion. These latter also showed a potential for metabolic inhibition mainly cytochrome P450-mediated in all cases. Here we demonstrated that human detoxification from a pesticide may be severely hampered in case of co-occurrence of other pesticides, as it is the case for drugs interactions, thus increasing the risk of adverse health effects. These results could contribute to improve the current challenging risk assessment of human and animal dietary to environmental chemical mixtures.
\end{abstract}

